\title{
Autobiographical memory and amnesia
}

\author{
DEAN F. MACKINNON and LARRY R. SQUIRE \\ Veterans Administration Medical Center, San Diego, California \\ and University of California School of Medicine, La Jolla, California
}

In four experiments, we assessed autobiographical memory in 5 normal subjects and in 5 memoryimpaired patients, all of whom had become amnesic on a known date. The patients were unable to produce autobiographical recollections in as much detail as the normal subjects could. The impairment was especially noticeable when single-word cues were used to elicit memories and when subjects were asked to recollect events from any past time period. Amnesic patients performed better when they were instructed to restrict their recollections to childhood or adolescence. In particular, when single-word cues were used together with probe questions, or when structured questions were used instead of single-word cues, amnesic patients produced recollections about childhood and adolescence that could not be distinguished qualitatively or quantitatively from the recollections of normal subjects. The patients who had the most difficulty recollecting autobiographical episodes were the same ones who in a previous study had exhibited the most severe and extensive retrograde amnesia on fact-memory tests. These findings do not support the view that amnesia especially affects episodic, as compared to semantic, memory. Isolated amnesic syndromes can have little effect on the storage and retrieval of very remote memories, whether they be memories for facts or memories for specific autobiographical episodes.

Descriptions of human amnesia suggest that early memories are better preserved than recent memories and are sometimes entirely intact (Barbizet, 1970; Milner, 1966; Ribot, 1881/1882; Talland, 1965). However, most assessments of remote memory test general factual knowledge, which is difficult to tie to a particular time period. Moreover, tests of factual knowledge often involve rather simple questions about material that was likely to have been well learned originally. Nevertheless, in the case of fact memory, the conclusion that material acquired long ago is intact in amnesia has received experimental support (Marslen-Wilson \& Teuber, 1975). In one recent study, amnesic patients performed normally even when factual questions about information in remote memory were so difficult that they could be answered by fewer than $20 \%$ of normal subjects (Squire, Haist, \& Shimamura, 1989).

Tests have also been developed in which subjects are asked to recall specific autobiographical episodes from the past. These tests have been of special interest because of proposals that autobiographical (episodic) memory differs fundamentally from general knowledge (semantic) memory (Tulving, 1983) and that amnesia reflects a selective loss of episodic memory (Kinsbourne, 1988; Parkin, 1982; Wood, Ebert, \& Kinsbourne, 1982). Many tests of autobiographical memory have depended on a

This research was supported by the Medical Research Service of the Veterans Administration, NIMH Grant 24600 , the Office of Naval Research, and the McKnight Foundation. We thank Joyce Zouzounis and Natacha Haist for research assistance, David Rubin for furnishing stimulus materials, and Art Shimamura, Stuart Zola-Morgan, and Endel Tulving for their helpful suggestions. Correspondence may be addressed to Larry R. Squire, Department of Psychiatry (116), Veterans' Administration Hospital, 3550 La Jolla Village Dr., San Diego, CA 92161. word-association technique originated by Galton (1879) and later revived by Crovitz and Schiffman (1974). Subjects are asked to recollect autobiographical episodes in response to a fixed list of cue words. Quantitative assessments of amnesic patients using this technique have found that some patients can recollect well-formed autobiographical episodes, although they often tend to draw them from earlier time periods than do normal subjects (Baddeley \& Wilson, 1986; Sagar, Cohen, Corkin, \& Growdon, 1985; Zola-Morgan, Cohen, \& Squire, 1983; ZolaMorgan, Squire, \& Amaral, 1986). At the same time, not all amnesic patients are capable of reconstructing normal episodes, and some patients are said to be unable to produce any episodes from their lives at all (Cermak \& O'Connor, 1983; Damasio, Eslinger, Damasio, Van Hoesen, \& Cornell, 1985; Tulving, Schacter, McLachlan, \& Moscovitch, 1988; Warrington \& McCarthy, 1988).

The present study was designed to obtain a reliable measure of autobiographical memory ability in a group of amnesic patients who had previously been evaluated with remote-memory tests for factual knowledge (Squire et al., 1989). In Experiment 1, we used the word-association method developed by Crovitz and Schiffman (1974) and 10 word cues in order to be able to relate the findings to previous studies using this method. In Experiment 2, we used the same word-association method and 75 cue words in order to identify the time periods from which amnesic patients tend to draw their recollections. In Experiment 3, we also used the word-association technique, but with instructions for the subjects to recollect only memories that had occurred during the first 21 years of their lives. In Experiment 4, we used structured questions to elicit autobiographical memories (Kopelman, Wilson, 
\& Baddeley, in press) that could have occurred at any time in the past or that would have occurred during the first 21 years of the subjects' lives.

\section{EXPERIMENT 1}

\section{Method}

Subjects

Amnesic patients. Four men (A.B., G.D., W.H., and L.M.) and 1 woman (M.G.) were tested (Table 1). A.B. became amnesic in 1976 following an anoxic episode during a cardiac arrest; G.D. became amnesic in 1983 following a period of hypotension that occurred during major surgery; L.M. became amnesic in 1984 as the result of a respiratory arrest that occurred during an epileptic seizure (for a single case report, see Beatty, Salmon, Bernstein, \& Butters, 1987); M.G. became amnesic in 1986 following a bilateral medial thalamic infarction, as identified by magnetic resonance (MR) imaging; W.H. became amnesic in 1986 from an unknown etiology. Amnesia developed during a period of 3 days at the most without known head traumas, seizure, or unconsciousness (for a single case report of W.H., see Salmon, Lasker, Butters, \& Beatty, 1988). For both L.M. and W.H., MR imaging has identified pathology in the hippocampal formation bilaterally (Press, Amaral, \& Squire, in press). Patients G.D. and A.B. were not available for MR studies, but the findings for 2 patients with similar etiologies (L.M. from the present study and R.B.; see Zola-Morgan et al., 1986) suggest that G.D. and A.B. are also likely to have sustained damage to the hippocampal formation.

As a group, these 5 patients had an average of 15.6 years of education. Immediate and delayed (12-min) recall of a short prose passage (Gilbert, Levee, \& Catalano, 1968) averaged 6.0 and 0 segments, respectively. All patients obtained a zero delayed score. Scores on other memory tests are shown in Table 2. Note that the scores on the word-recall test in Table 2 are above zero because on this test of immediate recall, several items can be retrieved from immediate memory, which is intact in amnesia. In addition, the mean score on the Dementia Rating Scale (Mattis, 1976) was 135.6 points (maximum $=144$, range $=130-143$ ), with most of the points lost on the memory subportion of the test (6.2 points). Additional neuropsychological data for these same patients and scores for matched control subjects for the tests reported here can be found elsewhere (Janowsky, Shimamura, Kritchevsky, \& Squire, 1989; Squire \& Shimamura, 1986). The control subjects in one study (Squire \& Shimamura, 1986) scored 7.6 and 6.4 on immediate and delayed prose recall, 30.3 and 20.6 on copy and reconstruction of the complex figure, $6.0,7.6$, and 8.9 on paired-associate learning, 10.7 and 29.1 on recall and recognition of 15 words, and 41.1 and 38.1 on 24-h recognition of words and faces.

Healthy control subjects. Four men and 1 woman were tested and served as a control group for the amnesic patients. All were employees or volunteers at the San Diego Veterans Administration Medical Center. They averaged 53.8 years of age, had 15.6 years of education, and obtained WAIS-R subtest scores of 24.2 for Information (compared with 22.0 for the patients) and 59.4 for Vocabulary (compared with $\mathbf{5 7 . 8}$ for the patients). Immediate and delayed (12-min) recall of a short prose passage (Gilbert et al., 1968) averaged 5.6 and 5.4 segments, respectively.

\section{Test and Procedure}

The subjects were read 10 concrete nouns one at a time (tree, nail, baby, ticket, bottle, flag, book, window, street, picture) and

Table 1

Description of Amnesic Patients

\begin{tabular}{llccccccc}
\hline & & \multicolumn{5}{c}{ WMS-R Scores } \\
\cline { 4 - 8 } Patient & $\begin{array}{c}\text { Age } \\
\text { (yr) }\end{array}$ & WAIS-R & $\begin{array}{c}\text { Attention/ } \\
\text { Concentration }\end{array}$ & Verbal & Visual & General & Delay \\
\hline A.B. & 50 & 119 & 87 & 62 & 72 & 54 & $<50$ \\
G.D. & 47 & 92 & 109 & 86 & 88 & 85 & 60 \\
M.G. & 56 & 111 & 111 & 82 & 68 & 69 & 50 \\
W.H. & 65 & 113 & 88 & 72 & 82 & 67 & $<50$ \\
L.M. & 57 & 111 & 132 & 87 & 96 & 90 & 65 \\
Mean & 55.0 & 109.2 & 105.4 & 77.8 & 81.2 & 73.0 & 55.0 \\
\hline
\end{tabular}

Note-The WMS-R does not provide numerical scores for subjects who score below 50 . Therefore, values below 50 were scored as 50 for computing group means. WAIS-R = Wechsler Adult Intelligence Scale-Revised Full Scale IQ; WMS-R = Wechsler Memory Scale-Revised.

Table 2

Performance of Patients on Standard Tests of Anterograde Amnesia

\begin{tabular}{lcccccc}
\hline Patient & $\begin{array}{c}\text { Diagram } \\
\text { Recall }\end{array}$ & $\begin{array}{c}\text { Paired } \\
\text { Associates }\end{array}$ & $\begin{array}{c}\text { Word } \\
\text { Recall }\end{array}$ & $\begin{array}{c}\text { Word } \\
\text { Recognition }\end{array}$ & $\begin{array}{c}50 \\
\text { Words }\end{array}$ & $\begin{array}{c}50 \\
\text { Faces }\end{array}$ \\
\hline A.B. & 4 & $1-1-2$ & $33 \%$ & $83 \%$ & 31 & 33 \\
G.D. & 6 & $2-1-2$ & $36 \%$ & $79 \%$ & 26 & 28 \\
M.G. & 0 & $0-0-2$ & $52 \%$ & $81 \%$ & 30 & 40 \\
W.H. & 1 & $0-0-0$ & $40 \%$ & $84 \%$ & 29 & 24 \\
L.M. & 11 & $1-1-3$ & $44 \%$ & $98 \%$ & 29 & 37 \\
\hline
\end{tabular}

Note-The Diagram Recall score is based on delayed (12-min) reproduction of the ReyOsterrieth figure (Osterrieth, 1944; maximum score $=36$ ). The average copy score was 28.6. The Paired Associates score is the number of noun-noun pairs recalled on three successive trials (maximum score $=10 /$ trial). The Word Recall score is the percentage of words recalled out of 15 across five successive study-test trials (Rey, 1964). The Word Recognition score is the percentage of words identified correctly across five successive study-test trials (yes/no recognition of 15 new words and 15 old words). The score for words and faces is based on a 24-h recognition test of 50 words or 50 faces (modified from Warrington, 1984; maximum score $=50$, chance $=25$ ). 
were asked to recollect an autobiographical episode that could be associated with each word. The same list of words and the same procecture were used in a previous study (Zola-Morgan et al., 1983). The subjects were told to select episodes from any time in their life but to describe an episode that could be remembered as having happened at a particular time and in a particular place. When a subject failed to provide a memory that was clearly specific to time and place, a score was recorded for the response produced up to that point, and the subject was then given probes to elicit the fullest possible response. Probing was done in two ways: (1) subjects were encouraged to be more specific about an already stated general memory (e.g., "How would you describe that trip to the hospital?"), and (2) if subjects could not begin to produce an episode, they were offered samples of concrete possibilities that might be helpful in generating one (e.g., "Maybe somebody gave you a bottle of wine $\ldots$ or you played spin the bottle ... or a time you dropped a bottle of something?'). Finally, when the subjects did describe a specific incident in response to a cue word, they were asked to estimate the date (month or season and the year) of the remembered event.

Subjects were tested in a single session, which was tape-recorded. The tapes were later scored by the experimenter and also by a second person, who was unacquainted with any of the subjects in the experiment. In addition, this second rater was unaware of the group membership of any of the subjects, and no names or other identifying remarks appeared on the tapes. Contrary to widespread impressions, amnesic patients do not continually give themselves away to examiners by talking about their memory problems, especially when they are subject to repeated testing over the years. The blindrating method was successful for Experiment 1; however, after scoring all the responses from three separate experiments, the rater was able to identify the amnesic patients (see below).

Four to 6 weeks after the test session, the subjects were read summaries of their responses to the word cues, and they were asked once again to provide the date (month or season and year) on which each remembered event occurred. These dates were compared with the dates given initially to assess the validity of the original recollections.

\section{Scoring}

Responses were scored in two ways. First, a binary ( 0 or 1$)$ score was recorded for each subject's 10 responses. A specific, detailed memory of an episode earned 1 point and a partial memory or a failure to recall earned 0 . Second, responses were scored according to a 0 to 3 scale, as described previously (Zola-Morgan et al., 1983). Three points were given for a specific, detailed memory of an episode (e.g., "It was freezing and there was snow on the ground and it was a little overpass that I was going over ... well, I went over the top going too fast. ... I did a little bit of spinning and twisting and what have you and fortunately no one was in the vicinity so I didn't hit anyone. ... I was pretty alarmed"). If the subject reported that a specific event had occurred, but could supply few or no details, 2 points were given (e.g., "When I was younger, broke my arm, fell out of an apple tree"). If a subject could report only an incident that had occurred on multiple occasions but could recall no single instance, only 1 point was given (e.g., "I used to go trout fishing with my Dad at Big Pine Lake"). A score of 0 was given whenever the response included no description of an episodic memory (e.g., "A book's a book"), or when the subject recalled nothing at all.

\section{Results}

All responses were scored independently by two raters. The scores assigned to the subjects by the two raters were well correlated, and separate Pearson correlation coefficients ranged from .83 to .98 [for the two subject groups, two different scoring methods $(0-1$ and $0-3)$, and two different conditions (without probes and with probes)]. Accordingly, for the data analysis, each subject was assigned the average of the two scores provided by each rater. Figure 1 shows autobiographical recall in response to the 10 cue words $(0-1$ scoring method, maximum score $=10$ ).

Figure 1A shows the scores derived from the first response produced by each subject (the without-probes condition). Figure 18 shows the scores derived from the most complete response that could be produced after receiving the help of probe questions (the with-probes condition). The amnesic patients were impaired in both conditions $[t \mathrm{~s}(8)>3.6$, ps $<.01]$. Without the help of probe questions, they were able to produce an average of only 1.2 episode-specific, autobiographical memories (maximum $=10$ ), whereas control subjects were able to produce 6.7 specific memories. With the help of probes, the amnesic patients produced 4.9 memories, and control subjects produced 9.4 . When the same responses were scored according to the $0-3$ scale, the results were similar. Without probes, the amnesic patients scored 13.3 (maximum $=30$ ), and the control subjects scored 24.6; with probes, the amnesic patients scored 22.9 , and the control subjects scored 29.4 [ts $(8)>2.9$, ps $<.05]$.

Both raters suggested independently that the amnesic patients may have been disadvantaged by a tendency to lose track of their narratives during the middle of a response. [Indeed, after scoring all the responses for Experiments 1,3 , and 4 , the second (blind) rater was able to identify the amnesic patients as those subjects who had this difficulty.] For example, in the course of recollecting a specific experience, many subjects would introduce contextual information or other material not strictly relevant to the scoring criteria. When the experimenter then used probe questions to steer the subject back to the specific memory that the subject had begun to report, control subjects typically resumed the recollection directly from the point at which it had been interrupted. However,
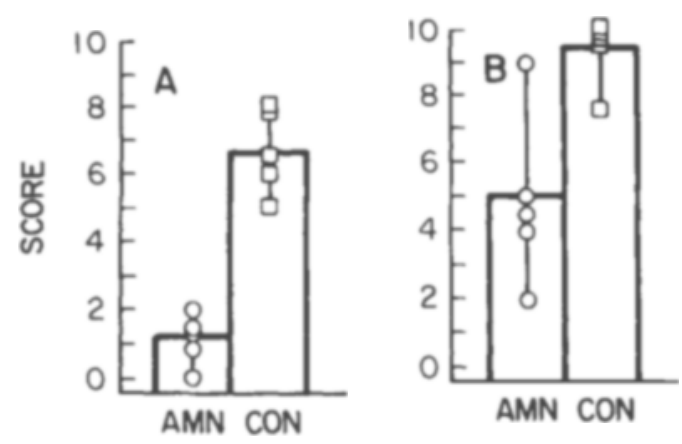

Figure 1. The number of specific, autobiographical memories produced in response to 10 single-word cues. (A) The score derived from the first response produced by each subject (without-probes condition). (B) The score derived from the most complete response that could be produced after receiving the help of probe questions (with-probes condition). Symbols show scores for individual subjects in each group. In (A), the amnesic patients from the highest score to the lowest) are A.B., L.M., M.G., G.D., and W.H. In (B), the order is A.B., M.G., G.D., L.M., and W.H. 
amnesic patients seldom resumed their recollections from the point of interruption. Instead, they were more likely to respond with short, factual statements without clear recognition that they had lost the narrative. Often they would repeat part of what they had already said, and sometimes they would begin an entirely new story. Perhaps as a result of these difficulties, the amnesic patients took longer than the control subjects to complete the test [48.0 min for amnesic patients vs. $26.0 \mathrm{~min}$ for control subjects; $t(8)=2.5, p<.05]$.

\section{Dating of Memories}

In the first testing session, the amnesic patients were able to assign dates to 42 memories, and the healthy control subjects could assign dates to 49 memories. (These were all the recollections that could be scored as a 2 or a 3 according to the 0-3 scale excepting four recollections for which the subjects were unwilling to estimate a date.) The two groups did not differ significantly in the average age of their recollections [28.9 years for the amnesic patients and 18.5 years for control subjects; $t(8)=$ $1.38, p>.10$ ]. However, relative to the control subjects, the amnesic patients drew a smaller proportion of their memories from the $1980 \mathrm{~s}[12.0 \%$ vs. $50.8 \%, t(8)=2.36$, $p<.05]$. Of 42 recollections that could be assigned dates, the amnesic patients reported only 5 that occurred during the 1980s (4 of these recollections were provided by a single patient). By contrast, the control subjects drew 25 of their 49 recollections from the 1980 s.

When summaries of these memories were presented again 4-6 weeks later, all subjects immediately recognized the memories they had dated earlier and again assigned dates to them. The absolute difference between the dates offered on the two occasions averaged 2 years for the amnesic patients and 0.5 years for the control subjects $[t(8)=2.5, p<.05]$. Thus, the amnesic patients had some difficulty assigning accurate dates to past events, consistent with the observation that their recollections on average were also poorer than those of the normal subjects. That is, the amnesic patients were impaired at both recollecting and dating episodic memories. Nevertheless, the observation that the discrepancy between dates on the two test occasions was numerically small, even for the am- nesic patients, suggests that most of the recollections were actual memories rather than fabrications. In Experiment 2, we explored in more detail the time periods from which amnesic patients draw their autobiographical memories.

\section{EXPERIMENT 2}

In this experiment, we used a pool of 75 word cues to determine from which past time periods episodic memories tend to be recalled.

\section{Method}

\section{Subjects}

The subjects were the same 5 amnesics and 5 control subjects who participated in Experiment 1.

\section{Test and Procedure}

We used 75 words (e.g., money, mother, joy, dog, discovery), selected from a larger set of $\mathbf{2 8 0}$ words kindly provided by David Rubin. These were read to the subject one at a time with the same instructions as in Experiment 1; namely, to produce a specific autobiographical memory associated with each word. Testing required two to five separate sessions, scheduled during a period of 1 to 4 weeks. Probe questions were asked as in Experiment 1, and responses were scored by the experimenter as they were produced. At the end of each session, all responses that had received a score of 2 or 3, according to the $0-3$ scoring system, were read back to the subject, and the subject was asked to assign a date to each of these responses. Assignment of dates was done at the end of each session, rather than after each response, to reduce the likelihood that the time period from which a memory was drawn would then influence the time period from which succeeding memories were drawn. The responses in this experiment were scored by one rater.

Two to 4 weeks after the final session, the subjects were read summaries of 10 of their original responses that had been scored as a $\mathbf{2}$ or a 3 , and they were asked once again to assign a date to each of these recollections. To select 10 responses, the subjects were read their responses to every fifth word cue, passing over word cues that had not produced a 2 or a 3 score. The 10 dates produced in this session were compared with the dates given originally for the same 10 memories.

\section{Results}

Figure 2 shows the time periods from which the amnesic patients and control subjects drew their recollections in response to the 75 cue words. The results were similar
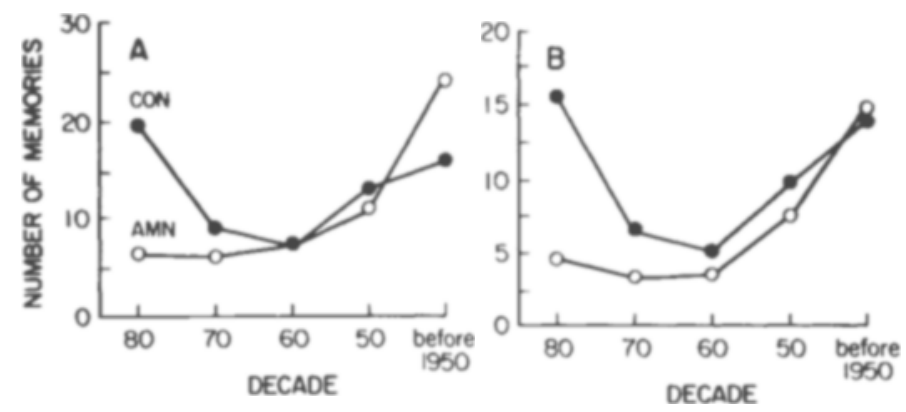

Figure 2. Time periods from which subjects drew their autobiographical memories in response to 75 single-word cues. (A) Temporal distribution of those recollections that could be dated, which were scored as a 2 or a 3 on the 0-3 scale. (B) Temporal distribution of those recollections that earned a full 3-point score. 
whether the data set included all the recollections that could be dated [i.e., those that were scored as a 2 or a 3 (Figure 2A)], or whether the data set included only recollections that earned a full 3-point score (Figure 2B). The amnesic patients produced a total of 55.0 recollections that could be scored as either a 2 or a 3 on the $0-3$ scale (maximum $=75$ ). The control subjects produced 65.2 such recollections. An analysis of variance indicated no group difference in number of recollections $[F(1,49)=$ $0.6, p>.1]$; however, the groups did differ in terms of the decade to which the recollections were assigned $[F(4,49)=3.9, p<.01]$. There was no group $\times$ time period interaction $[F(4,49)=2.0, p>.1]$. The amnesic patients produced 33.6 recollections that were considered sufficiently detailed and specific to earn a full 3-point score (maximum $=75$ ). For the control subjects, 51.6 recollections earned a 3-point score. The effects of group $[F(1,49)=4.8, p<.05]$ and time period $[F(4,49)=$ $4.9, p<.01$ ] were significant, but there was no group $\times$ time period interaction $[F(4,49)=1.4, p>.1]$. Thus, as in Experiment 1, the amnesic patients could produce fewer well-formed (3-point) episodic memories than could the control subjects.

Although there was no group $\times$ time period interaction, the amnesic patients produced fewer recollections from the 1980s than did the control subjects [Figure $2 \mathrm{~A}$, $t(8)=2.5, p<.05$; Figure $2 \mathrm{~B}, t(8)=2.9, p<.05]$. The distribution of memories in the other time periods (from before 1950 to 1979) was similar for the two groups ( $p s>.10)$. Overall, the results suggest that the amnesic patients produced fewer recollections from the most recent decade than did the control subjects, but they produced a normal number of recollections from the more remote time periods.

Figure 3 shows the 2- and 3-point recollections produced by the amnesic patients in relation to the date of onset of their amnesia. For each patient, the shaded regions represent the period of anterograde amnesia. Two patients (M.G. and W.H.) produced no memories from their period of anterograde amnesia, and L.M. produced only one memory. These 3 patients (L.M., M.G., and W.H.) also produced a combined total of only four recollections from the 10 years immediately preceding the onset of their amnesia. The two remaining patients (A.B. and G.D.) produced several memories from the period of their anterograde amnesia and also produced some memories from the 10 years preceding the onset of their amnesia. In general, recollections became more frequent in the more remote time periods.

In the course of testing, all subjects constructed a time line of major life events by arranging along a horizontal line major life events in the order that they had occurred. Two of the patients (A.B. and W.H.) used the time line to help them assign dates to their memories. The other patients and the control subjects did not seem to need a time line to date their memories. A.B. recounted readily

\begin{tabular}{|c|c|c|c|c|c|c|c|c|c|c|}
\hline \multicolumn{11}{|c|}{ RECOLLECTIONS IN EACH TIME PERIOD } \\
\hline Year & $A B$ & GD & LM & MG & WH & $\mathrm{Cl}$ & $\mathrm{C} 2$ & $\mathrm{C3}$ & C4 & C5 \\
\hline 1987 & 4 & 5 & 0 & 0 & 0 & 5 & 9 & 12 & 7 & 1 \\
\hline 1986 & 3 & 3 & 1 & 0 & 0 & 4 & 4 & 1 & 7 & 0 \\
\hline 1985 & 4 & 3 & 0 & 0 & 0 & 4 & 8 & 2 & 0 & 0 \\
\hline 1984 & 1 & 0 & 0 & 1 & 0 & 0 & 2 & 0 & 3 & 4 \\
\hline 1983 & 1 & 1 & 0 & 0 & 0 & 1 & 0 & 1 & 1 & 0 \\
\hline 1982 & 1 & 1 & 0 & 0 & 0 & 1 & 2 & 1 & 0 & 0 \\
\hline$|98|$ & 0 & 0 & 0 & 0 & 0 & 1 & 1 & 4 & 0 & 1 \\
\hline 1980 & 2 & 2 & 0 & 0 & 0 & 2 & 1 & 5 & 2 & 1 \\
\hline 1979 & 0 & 0 & 0 & 0 & 0 & 2 & 0 & 0 & 1 & 2 \\
\hline 1978 & 0 & 4 & 0 & 0 & 0 & 3 & 0 & 1 & 0 & 0 \\
\hline 1977 & 1 & 0 & 0 & 2 & 1 & 0 & 0 & 0 & 0 & 0 \\
\hline $\begin{array}{l}1970- \\
1976\end{array}$ & 6 & 7 & 0 & 8 & 2 & 3 & 6 & 22 & 2 & 3 \\
\hline $\begin{array}{l}1950- \\
1969 \\
\end{array}$ & 25 & 18 & 9 & 33 & 8 & 26 & 25 & 16 & 21 & 14 \\
\hline $\begin{array}{c}\text { Before } \\
1950\end{array}$ & 21 & 2 & 46 & 19 & 34 & 18 & 10 & 1 & 27 & 25 \\
\hline TOTAL & 69 & 46 & 56 & 63 & 45 & 70 & 68 & 66 & 71 & 51 \\
\hline
\end{tabular}

Figure 3. Temporal distribution of recollections by each amnesic patient and each control subject (C1-C5). These data represent all the recollections that could be dated and that were scored as either a 2 or a 3 on the $0-3$ scale. The shaded portion of the figure denotes the years during which each patient had amnesia.

all major school and work milestones up to the onset of his amnesia in 1976. After consulting a card in his wallet, he then added the 1983 installation of his cardiac pacemaker. G.D. listed a few early milestones, then "1958-1977-active (US Navy)," and closed with the events that precipitated his amnesia. L.M.'s list contained an even distribution of personal milestones, ending with "1984-seizures finally got the best of me-amnesia." M.G. outlined in great detail personal milestones up to the birth of her first child in 1951; after 1951, her list of events lost chronological order. The last event that she recorded occurred in 1965. W.H. was able to assign dates to a few major events until 1955, after which time he was unable to state the order of the companies he worked for or the years he worked for them. The 5 control subjects all completed time lines with an even distribution of events. They experienced no confusion and in each case concluded by listing events that had occurred during the past few years.

When asked 2 to 4 weeks later to redate a sample of 10 of their memories, the amnesic patients varied from their previous estimates by an average of 1.6 years, and the control subjects varied by an average of 0.8 years 
$[t(8)=2.7, p<.05]$. Although this difference was significant, it was small enough to suggest that most of the recollections were memories rather than fabrications.

\section{EXPERIMENT 3}

Experiments 1 and 2 showed that amnesic patients had difficulty recollecting specific autobiographical episodes and that, in addition, their successful recollections tended to be drawn from relatively early time periods. In Experiment 3, we asked whether amnesic patients might perform better if they were instructed explicitly to recall episodes only from their early life.

\section{Method}

\section{Subjects}

The subjects were the same 5 amnesic patients and 5 control subjects who participated in Experiments 1 and 2.

\section{Test and Procedure}

The test was identical to the test described in Experiment 1, except that a different list of 10 words was used (dog, store, school, chair, orange, lamp, pencil, hammer, leg, train). The test was administered just as in Experiment 1, except that now the subjects were asked to report and date only episodes that had occurred when they were 21 years of age or younger. In all other respects, the procedure was the same as in Experiment 1, except that the memories that were collected were not redated in a subsequent session. Thus, probe questions were used, responses were dated, and responses were scored according to a $0-1$ and a $0-3$ scale. All subjects were scored independently by the same two raters who participated in Experiment 1.

\section{Results}

The scores assigned to the subjects by the two raters were well correlated (Pearson correlations ranged from .75 to .95 for the two subject groups, two different scoring methods, and two different probe conditions). For the data analysis, each subject was assigned the average of the two scores provided by each rater.

Figure 4 shows autobiographical recall for episodes that had occurred when the subjects were 21 years old or younger $(0-1$ scoring method, maximum score $=10)$. Figure 4A shows the scores derived from the first response produced by each subject (the without-probes condition), and Figure $4 \mathrm{~B}$ shows the scores derived from the most complete response that could be produced after receiving the help of probe questions (the with-probes condition). Without the help of probe questions, the amnesic patients produced an average of 2.2 episode-specific, autobiographical memories (maximum $=10$ ), whereas the control subjects were able to produce 5.2 specific memories $[t(8)=2.9, p<.05]$. With the help of probes, the amnesic patients produced 5.5 memories, and the control subjects produced $7.1[t(8)=1.4, p>.1]$.

When the responses were scored according to the 0-3 scale (maximum score $=30$ ), the results were similar. Specifically, the scores were 15.1 versus 21.3 , respectively, for the amnesics and control subjects in the withoutprobes condition [maximum score $=30 ; t(8)=2.5$,
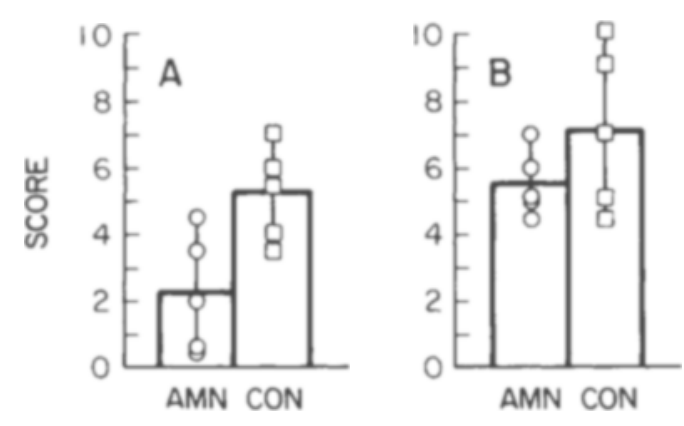

Figure 4. The number of specific, autobiographical memories produced in response to 10 single-word cues. Subjects were instructed to report only recollections of events that occurred when they were 21 years old or younger. (A) The score derived from the first response produced by each subject (without-probes condition). (B) The score derived from the most complete response that could be produced after receiving the help of probe questions (with-probes condition). Symbols show scores for individual subjects in each group. In (A), the amnesic patients (from the highest score to the lowest) are L.M., G.D., A.B., M.G., and W.H. In (B), the order is L.M., A.B., G.D., M.G., and W.H.

$p<.05$ ] and 22.8 versus 25.9 , respectively, in the withprobes condition $[t(8)=1.5, p>.1]$. The ages of the memories produced by the two groups were similar (amnesics, 43.8 years; controls, 43.0 years; $p>.1$ ). On average, the amnesic patients were 11.0 years old at this time, and the control subjects were 11.2 years old. Thus, with specific instructions to draw their recollections from childhood and adolescence, and with the help of probe questions, the amnesic patients produced as many detailed autobiographical memories as did the control subjects. In the next experiment, we asked whether autobiographical recall would also be aided when structured questions, instead of single-word cues, were used to elicit recollections.

\section{EXPERIMENT 4}

\section{Method}

\section{Subjects}

The same 5 amnesic patients and 5 control subjects who participated in Experiments 1-3 served as subjects in this experiment.

\section{Test and Procedure}

We compiled two lists of direct questions about common events that are likely to have been encountered by most persons. The first list consisted of 15 events that could have occurred at any time, either recently or long ago (e.g., "Tell me as much as you can about: your best athletic performance, the best birthday surprise you've had, the longest drive you took in one day, the worst time you ever got lost'). The second list consisted of 15 events that would have occurred in childhood or adolescence (e.g., "Tell me as much as you can about: your most embarrassing moment in high school, the day you first got your driver's license, the day you learned to ride a bike").

Because the subjects could not be expected to have had an experience relevant to every test item, each item was preceded by a screening question. For example, if the test question was, "Tell me as much as you can about the best wedding you have attended as a guest," then that item was introduced by the screening ques- 
tion, "Have you ever attended a wedding as a guest?" If the subject answered "no" to the screening question, then that item was scored as a "pass," and no score was entered for that item. If the answer to the screening question was "yes," then the subject's response was recorded and scored according to the 0-1 and 0-3 rating scales, as described above (see Experiment 1). Encouragement was limited to offering neutral remarks (e.g., "Can you tell me anything more about that?" "Is there anything else you can remember?").

Items were presented from the first list until each subject had been given 10 items, excluding items that were "passed." Then, items were presented from the second list until each subject had been given 5 items, excluding items that were "passed." Two sessions were required to complete the testing. All sessions were tape-recorded and scored by two raters, as described above.

\section{Results}

The correlations between the scores assigned to the subjects by the two raters ranged from .64 to .95 (for the two groups and two scoring systems). Each subject was assigned the average of the two scores provided by the raters. Figure 5A shows recall of autobiographical episodes in response to 10 questions from the first list, that is, questions about events that could have occurred at any time (0-1 scoring method, maximum score $=10$ ). Figure 5B shows recall of autobiographical episodes in response to five questions from the second list, that is, questions about events that occurred during childhood or adolescence ( $0-1$ scoring method, maximum score $=5$ ). The amnesic patients and the control subjects were similar with respect to how many questions had to be passed in order to identify 10 questions for the first phase of the experiment (Figure 5A) and five questions for the second phase (Figure 5B). The amnesic patients passed on 4.6 questions in the course of identifying 15 appropriate questions, and the control subjects passed on 3.6 questions $[t(8)=0.6, p>.1]$.

The amnesic patients recalled fewer well-formed episodes than did the control subjects when questions were
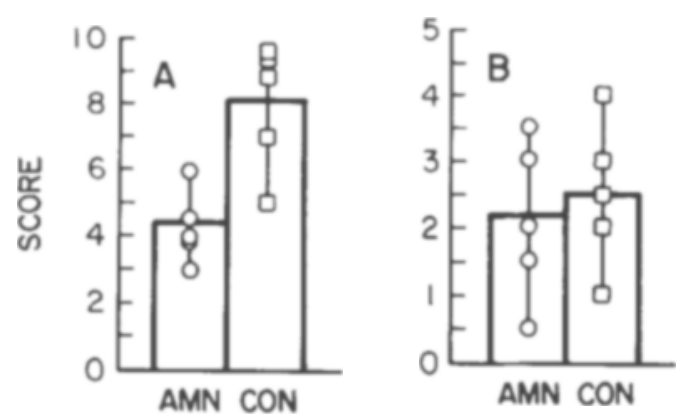

Figure 5. The number of specific, autobiographical memories produced in response to structured questions about events likely to have been encountered by most subjects. (A) The number of specific memories produced in response to 10 questions about events that could have occurred at any time. (B) The number of specific memories produced in response to 5 questions about events that would have occurred during childhood or adolescence. Symbols show scores for individual subjects in each group. In (A), the amnesic patients (from the highest score to the lowest) are A.B., G.D., M.G., W.H., and L.M. In (B), the order is A.B., L.M., W.H., M.G., and G.D. not restricted with regard to time period [Figure 5A, 4.3 vs. 8.0, maximum score $=10, t(8)=3.7, p<.01$; on the $0-3$ scale, 20.7 vs. 26.2 , maximum score $=30$, $t(8)=2.3, p<.05]$. However, when questions were directed at events of childhood or adolescence, the amnesic patients and the control subjects performed similarly. On the 0-1 scale (Figure 5B), the amnesic patients scored 2.1 and the control subjects scored 2.5 [maximum score $=5, t(8)=0.5, p>.1]$. On the $0-3$ scale $(\max -$ imum score $=15$ ), the results were the same $[8.8$ vs. 9.7 , $t(8)=0.4, p>.1]$. Both groups received a 0 score on 1.2 out of the 5 test items.

\section{DISCUSSION}

In this study, we assessed the ability of amnesic patients to produce specific autobiographical recollections. Experiment 1 showed that amnesic patients produced fewer wellformed recollections than did control subjects in response to 10 single-word cues, even when they had the benefit of probe questions. Experiment 2 confirmed this finding for 75 additional single-word cues. The temporal distribution of the recollections suggests that amnesic patients had difficulty primarily in drawing recollections from the 1980 s and progressively less difficulty in drawing recollections from earlier periods. The temporal distribution of the recollections provided by control subjects was Ushaped, in agreement with previous studies with this test involving normal middle-aged subjects (McCormick, 1979).

Experiment 3 showed that amnesic patients and control subjects performed similarly in response to 10 single-word cues when they were asked with the benefit of probe questions to recollect only events that occurred when they were 21 years old or younger. In Experiment 4, recollections were cued with structured questions instead of with single words. Amnesic patients performed more poorly than control subjects when the structured questions asked about events that could have occurred at any time. The two groups performed similarly when the questions asked about events that occurred during childhood or adolescence.

A three-way analysis of variance was carried out to evaluate how amnesic patients and control subjects were affected across all the experiments by changes in instructions (recall from any time period vs. recall from early life) and by changes in cue type (single words vs. structured questions). This analysis included the data in Figures 1A, 4A, 5A, and 5B (the data in Figure 5B, which were based on only 5 test items instead of 10 , was doubled for the purpose of this analysis). In addition to the expected effect of group $(p<.01)$, there was an effect of both cue type $[F(1,8)=12.1, p<.01]$ and time period $[F(1,8)=5.5, p<.05]$. The effect of cue type (Figure 1A vs. 5A and Figure 4A vs. 5B) was due to the fact that the amnesic patients, but not the control subjects, did better when cued by structured questions than when cued by single words [interaction of group $\times$ cue type, $F(1,8)=5.0, p=.05]$. The effect of time period (Figure 1A vs. 4A and Figure 5A vs. 5B) was due to the 
fact that the control subjects did better when they were able to recollect events from any time period than when they were instructed to recall events from early life, whereas the amnesic patients did somewhat better when they were restricted to early time periods [interaction of group $\times$ time period, $F(1,8)=12.4, p<.01]$. No other interaction approached significance $(p s>.1)$.

The results from all four experiments showed that, on average, amnesic patients were unable to produce autobiographical recollections in as much detail as normal subjects could. However, when the subjects were instructed to restrict their recollections to memories of childhood or adolescence, amnesic patients performed more similarly to normal subjects. Indeed, amnesic patients and control subjects were not distinguishable when probe questions were used together with single-word cues (Experiment 3, Figure 4B) or when structured questions were used (Experiment 4, Figure 5B). At the same time, it should be noted that the data are based on a small number of subjects and that, even for those comparisons that did not approach significance, the mean score obtained by the amnesic patients was numerically less than the mean score obtained by the control subjects. Nevertheless, within the limits of our ability to score responses, recollections about childhood or adolescence were quantitatively and qualitatively similar in the two groups.

It is not clear why remote memories could be retrieved well only when probe questions or sufficiently structured questions were provided. One possibility is that amnesic patients have a general difficulty in memory retrieval, which affects remote memories as well as recent ones, and that this difficulty can be largely circumvented by appropriately structured questions. If so, this difficulty occurs only when narrative, autobiographical responses are required, as in the present study, and not when short, factual answers to general-information questions are required, as in a previous study involving the same amnesic patients (Squire et al., 1989). Alternatively, it is possible that some of the difficulty that the amnesic patients had in producing specific, detailed recollections was related to their anterograde amnesia. The patients seemed to have difficulty holding one part of a recollection in mind while they searched for other parts, and they had difficulty returning to a partially reconstructed memory after hearing a probe question. Anterograde amnesia might have less impact on accessing early memories, relative to recent memories, because early memories are more stable than recent memories and are more fixed in their associative links, as shown originally by Galton (1879).

These findings for autobiographical memory are in agreement with results recently reported for the same 5 patients on two tests of remote memory for public events (Squire et al., 1989). As a group, these 5 patients exhibited temporally limited retrograde amnesia covering the 1970s and the 1980s, and normal recall for events that occurred prior to 1970 . In that study, W.H. and G.D. exhibited severe and extensive retrograde amnesia on both tests, M.G. exhibited extensive retrograde amnesia on one test, and L.M. and A.B. exhibited less retrograde amnesia. In the current study, A.B. and L.M. also performed best overall, whereas W.H. performed the worst. It therefore seems possible that, among amnesic patients, the extent and severity of retrograde amnesia for autobiographical (episodic) memory parallels the extent and severity of retrograde amnesia for knowledge (semantic) memory.

The current findings differ in one important respect from results reported previously for 7 patients with alcoholic Korsakoff's syndrome (Zola-Morgan et al., 1983). Those patients, who were tested exactly as in Experiment 1 of the current study, performed almost the same as the current group of amnesic patients (without probesKorsakoff patients, 2.1 out of 10; current group of patients, 1.2 ; with probes-Korsakoff patients, 5.4 ; current group of patients, 4.9). However, in the earlier study, the Korsakoff patients did not score significantly lower than alcoholic control subjects (5.4 vs. 7.5 ). In the current study, the amnesic patients scored significantly lower than the control subjects (4.9 vs. 9.5 ).

Temporally graded retrograde amnesia appeared rather extensive in the current study, as well as in a related study of fact memory that involved the same amnesic patients (Squire et al., 1989). Thus, temporally graded retrograde amnesia can clearly be more extensive than was suggested by earlier work (Cohen \& Squire, 1981; Squire, Cohen, \& Nadel, 1984; Squire, Slater, \& Chace, 1975). Retrograde amnesia can appear limited when recognitionmemory tests are used (Squire et al., 1989; Squire et al., 1975), or when amnesia results from circumscribed damage to the hippocampus (Zola-Morgan et al., 1986). As discussed previously (Squire et al., 1989), more extensive, temporally graded retrograde amnesia covering a decade or more may require damage in addition to the hippocampus proper, perhaps damage involving adjacent, anatomically related cortex. In the nonhuman primate, memory impairment associated with hippocampal-formation lesions is increased by including additional, more rostral structures in the surgical removal (Mishkin, 1978; Squire \& Zola-Morgan, 1988).

Other studies have also found that very remote memory for autobiographical material can be preserved in amnesia. Notably, patient H.M., who is severely amnesic as the result of bilateral surgical resection of the medial temporal lobe carried out when he was 27 years old, was able to produce well-formed autobiographical memories from his adolescence (Sagar et al., 1985). Moreover, patient R.B., who had amnesia following a bilateral ischemic lesion limited to the CA1 region of the hippocampus, was entirely normal on the same autobiographical memory test used in the present study (Zola-Morgan et al., 1986). Finally, in a study of a mixed group of 10 amnesic patients (Baddeley \& Wilson, 1986) that used several measures of autobiographical memory, 2 patients with Korsakoff's syndrome and one postencephalitic patient had normal recollections of early memories. The other 7 patients had had either a stroke or a head injury and were therefore unlikely to have particularly selective amnesias. Three 
were described as having "clouding" of autobiographical memory, and 4 were described as having difficulties secondary to frontal lobe dysfunction.

Amnesic patients have also been reported who seemed quite unable to produce autobiographical recollections from any part of their lives. The head-injured patient K.D. (Tulving et al., 1988) was unable to recollect any personal episodes from his life at all. Similarly, the postencephalitic patient Boswell (formerly known as D.R.B.) (Damasio et al., 1985) was unable to produce any personal episodes. In both of these cases, extensive retrograde amnesia was tentatively linked to damage to neocortex. Finally, the postencephalitic patients S.S. and R.F.R. (Cermak \& O'Connor, 1983; Warrington \& McCarthy, 1988) are reported to have access to some personal knowledge about their past but not to particular episodes.

In general, the findings with autobiographical (episodic) memory tests seem to correspond to the findings with general knowledge (semantic) memory tests. On the one hand, patients who show an extensive, pervasive, and ungraded remote-memory impairment on tests of fact memory also cannot recollect specific episodes from their past (Cermak \& O'Connor, 1983; Damasio et al., 1985). On the other hand, those same patients who exhibit a temporal gradient of retrograde amnesia on fact-memory tests (i.e., patients for whom very remote factual information is intact) (Squire et al., 1989) can also recall early autobiographical episodes. Within this latter group, 1 patient in the present study who exhibited severe and extensive retrograde amnesia for factual information (Patient W.H.) also had the most difficulty recollecting autobiographical episodes. Moreover, the 2 patients who performed the best on the factual tests (A.B. and L.M.) also performed the best on the autobiographical tests. One possibility is that early memory for specific autobiographical episodes remains intact so long as damage is restricted to the medial temporal region itself or to the diencephalic midlinebrain areas traditionally linked to isolated amnesic syndromes. For example, patient R.B.'s damage was restricted to the CAl region of the hippocampus, and he exhibited intact autobiographical memory for premorbid events (Zola-Morgan et al., 1986).

These considerations are incompatible with the hypothesis (Kinsbourne, 1988; Parkin, 1982; Wood et al., 1982) that amnesia can be viewed as a dissociation between episodic and semantic memory. First, amnesic patients have difficulty recollecting recently acquired factual information (Gabrieli, Cohen, \& Corkin, 1988; Shimamura \& Squire, 1987; Squire et al., 1989) in the absence of any indication that episodic memory is ordinarily required for successful recall of such information. That is, in factmemory tests, there is little basis for supposing that retrieval always depends on bringing to mind the episode in which the knowledge was acquired. Second, as the present study shows, amnesic patients can succeed at recollecting personal memories from their early lives, even when it appears that they do so by retrieving specific episodes in which events occurred (see also Baddeley \& Wilson, 1986; Sagar et al., 1985; Zola-Morgan et al., 1986). Finally, as the present study and our recent study of fact memory (Squire et al., 1989) show, the severity of both kinds of memory failure (episodic and semantic) appears to be associated in individual patients (see also Beatty et al., 1987; Butters \& Cermak, 1986; Gabrieli et al., 1988; Kopelman et al., in press; Ostergaard, 1987).

The present findings support the idea that very early memory can be intact in amnesia. It remains of considerable theoretical importance to study the quality of the early recollections provided by amnesic patients as well as to compare and contrast the quality of remote and recent recollections provided by normal subjects. The question of interest is why the passage of time renders memories relatively independent of the medial temporal and diencephalic structures damaged in amnesia. If these structures perform specific computations necessary for memory formation, storage, and retrieval, why are these computations no longer needed for storage or retrieval when memories are old? One possibility is that old memories, for the most part, have lost the features that make retrieval dependent on the structures damaged in amnesia. By this view, memories gradually and normally lose certain qualities (e.g., the degree to which they are embedded in time-and-place context) that initially make them dependent on the damaged structures. If so, further study might reveal some qualitatively abnormal features in the early recollections of even the most selectively impaired amnesic patients. Moreover, in normal subjects, recent memories might exhibit certain qualities or features that are found less often in very remote memories. Thus, by this view, time per se is important in memory only because the amount of time that has passed since learning will tend to correlate with the quality of recollections (for a similar view, see Cermak, 1984).

Alternatively, old memories may be spared because of positive changes that occur with the passage of time (Squire, 1987). For example, rehearsal or subsequent encounters with similar material, or even quasi-random neural activity across time, might serve to strengthen some aspects of representations or to establish additional representations. Thus, although forgetting occurs, memories could gradually acquire some new qualities and, through this process of reorganization and consolidation, could become eventually independent of the structures damaged in amnesia.

\section{REFERENCES}

Baddeley, A., \& Wilson, B. (1986). Amnesia, autobiographical memory and confabulation. In D. Rubin (Ed.), Autobiographical memory (pp. 225-252). Cambridge: Cambridge University Press.

BARBIZET, J. (1970). Human memory and its pathology. New York: Freeman.

Beatty, W. M., Salmon, D. P., Bernstein, N., Butters, N. (1987). Remote memory in a patient with amnesia due to hypoxia. Psychological Medicine, 17, 657-665.

Butters, N., Cermak, L. S. (1986). A case study of the forgetting of autobiographical knowledge: Implications for the study of retro- 
grade amnesia. In D. Rubin (Ed.), Autobiographical memory (pp. 253272). Cambridge: Cambridge University Press.

Cermak, L. S. (1984). The episodic/semantic distinction in amnesia. In L. R. Squire \& N. Butters (Eds.), The neuropsychology of memory (pp. 55-62). New York: Guilford.

Cermak, L. S., O'Connor, M. (1983). The anterograde and retrograde retrieval ability of a patient with amnesia due to encephalitis. Neuropsychologia, 21, 213-234.

Cohen, N. J., SQuire, L. R. (1981). Retrograde amnesia and remote memory impairment. Neuropsychologia, 19, 337-356.

Crovitz, H. F., \& SchiffMan, H. (1974). Frequency of episodic memories as a function of their age. Bulletin of the Psychonomic Society, 4, 517-518.

Damasio, A. R., Eslinger, P. J., Damasio, H., Van Hoesen, G. W., \& CoRnell, S. (1985). Multimodal amnesic syndrome following bilateral temporal and basal forebrain damage. Archives of Neurology, 42, 252-259.

Gabrieli, J. D. E., Cohen, N., \& Corkin, S. (1988). The impaired learning of semantic knowledge following medial temporal-lobe resection. Brain \& Cognition, 7, 157-177.

Galton, F. (1879). Psychometric experiments. Brain, 2, 149-162.

Gilbert, J., Levee, R., \& Catalano, F. (1968). A preliminary report on a new memory scale. Perceptual \& Motor Skills, 27, 277-278.

Janowsky, J., Shimamura, A. P., KrTtchevsky, M., \& SQuire, L. R. (1989). Cognitive impairment following frontal lobe damage and its relevance to human amnesia. Behavioral Neuroscience, 103, 548-560.

KINSBOURNE, M. (1988). Brain mechanisms and memory. Human Neurobiology, 6, 81-92.

Kopelman, M. D., Wilson, B., \& Baddeley, A. D. (in press). The autobiographical memory interview: A new assessment of autobiographical and personal semantic memory in amnesic patients. Journal of Clinical \& Experimental Neuropsychology.

MARSLEN-Wilson, W. D., \& Teuber, H.-L. (1975). Memory for remote events in anterograde amnesia: Recognition of public figures from news photographs. Neuropsychologia, 13, 353.

MAtTIs, S. (1976). Dementia rating scale. In R. Bellack \& B. Karasu (Eds.), Geriatric psychiatry (Vol. 1, pp. 77-121). New York: Grune \& Stratton.

MCCormick, P. D. (1979). Autobiographical memory in the aged. Canadian Journal of Psychology, 33, 118-124.

Milner, B. (1966). Amnesia following operation on temporal lobes. In C. W. M. Whitty \& O. Zangwill (Eds.), Amnesia (pp. 109-133). London: Buttersworth.

Mishkin, M. (1978). Memory in monkeys severely impaired by combined but not by separate removal of amygdala and hippocampus. Nature, 273, 297-298.

OsTERGAARD, A. L. (1987). Episodic, semantic, and procedural memory in a case of amnesia at an early age. Neuropsychologia, 25, 341-357.

OSTERRIETH, P. (1944). Le test de copie d'une figure complexe. Archives of Psychology, 30, 206-356.

PARKIN, A. J. (1982). Residual learning capability in organic amnesia. Contex, 18, 417-440.

Press, G., Amaral, D. G., SQuire, L. R. (in press). The neurology of memory: A high resolution magnetic resonance imaging protocol reveals reduced size of the hippocampal formation in amnesic patients. Nature.
REY, A. (1964). L'examen clinique en psychologie. Paris: Presses Universitaires de France.

Riвot, T. (1882). Diseases of memory (W. H. Smith, Trans.). New York: Appleton-Century-Crofts. (Original work published 1881)

Sagar, H. H., Cohen, N. J., Corkin, S., \& Growdon, J. M. (1985). Dissociations among processes in remote memory. In D. S. Olton, E. Gamzu, \& S. Corkin (Eds.), Memory dysfunctions. Annals of the New York Academy of Sciences, 444, 533-535.

Salmon, D. P., Lasker, B. R., Butters, N., \& Beatty, W. W. (1988). Remote memory in a patient with circumscribed amnesia. Brain \& Cognition, 7, 201-211.

ShimamurA, A. P., SQUIRE, L. R. (1987). A neuropsychological study of fact memory and source amnesia. Journal of Experimental Psychology: Learning, Memory, \& Cognition, 13, 464-473.

SQuire, L. R. (1987). Memory and brain. New York: Oxford University Press.

SQuire, L. R., Cohen, N. J., NADEL, L. (1984). The medial temporal region and memory consolidation: A new hypothesis. In $\mathrm{H}$. Weingartner \& E. Parker (Eds.), Memory consolidation (pp. 185-210). Hillsdale, NJ: Erlbaum.

Squire, L. R., Haist, F., \&himamura, A. P. (1989). The neurology of memory: Quantitative assessment of retrograde amnesia in two groups of amnesic patients. Journal of Neuroscience, 9, 828-839.

SQuire, L. R., Shimamura, A. P. (1986). Characterizing amnesic patients for neurobehavioral study. Behavioral Neuroscience, 100, 866-877.

Squire, L. R., Slater, P. C., \& Chace, P. M. (1975). Retrograde amnesia: Temporal gradient in very long-term memory following electroconvulsive therapy. Science, 187, 77-79.

Souire, L. R, Zola-Morgan, S. (1988). Memory: Brain systems and behavior. Trends in Neurosciences, 11, 170-175.

Talland, G. A. (1965). Deranged memory. New York: Academic Press.

Tulving, E. (1983). Elements of episodic memory. Oxford: Clarendon Press.

Tulving, E., Schacter, D. L., Mclachlan, D. \& Moscovitch, M. (1988). Priming of semantic autobiographical knowledge: A case study of retrograde amnesia. Brain \& Cognition, 8, 3-20.

W ARRINGTON, E. K. (1984). Recognition memory test. Windsor, ON: NFER-Nelson.

Warrington, E. K., MCCARTHY, R. A. (1988). The fractionation of retrograde amnesia. Brain \& Cognition, 7, 184-200.

WoOd, F., EberT, V., KInsbourne, M. (1982). The episodicsemantic memory distinction in memory and amnesia: Clinical and experimental observations. In L. S. Cermak (Ed.), Human memory and amnesia (pp. 167-194). Hillsdale, NJ: Erlbaum.

Zola-Morgan, S., Cohen, N. J., SQUiRe, L. R. (1983). Recall of remote episodic memory in amnesia. Neuropsychologia, 21, 487-500.

Zola-Morgan, S., SQuire, L. R., \& Amaral, D. G. (1986). Human amnesia and the medial temporal region: Enduring memory impairment following a bilateral lesion limited to field CA1 of the hippocampus. Journal of Neuroscience, 6, 2950-2967.

(Manuscript received March 1, 1989; revision accepted for publication May 5, 1989.) 